\title{
Distribuição hídrica no período crítico do milho e produção de grãos
}

\author{
Homero Bergamaschi $^{(1)}$ Genei Antonio Dalmago ${ }^{(1)}$, João Ito Bergonci( ${ }^{(1)}$, Cleusa Adriane Menegassi Bianchi ${ }^{(1)}$,
} Artur Gustavo Müller(2), Flávia Comiran ${ }^{(1)}$, Bruna Maria Machado Heckler ${ }^{(1)}$

(1)Universidade Federal do Rio Grande do Sul, Caixa Postal 776, CEP 91501-970 Porto Alegre, RS. E-mail: homerobe@ufrgs.br (2)Universidade de ljuí, Rua São Francisco, 501, São Geraldo, CEP 98700-000 ljuí, RS. E-mail: agmuller@main.unijui.tche.br

Resumo - A cultura do milho pode sofrer reduções na produção de grãos quando há déficit hídrico no período crítico do ciclo da cultura, que ocorre desde o pendoamento até o início de enchimento de grãos. O objetivo deste trabalho foi estabelecer relações entre o suprimento de água durante o período crítico do milho e a produção de grãos. Experimentos foram conduzidos em Eldorado do Sul, RS (305'S; 514ㅇ' W; 40 m altitude), nas safras 1998/1999 e 2002/2003, anos em que ocorreram os fenômenos La Niña e El Niño, respectivamente. Os dados de rendimento de grãos e seus componentes foram obtidos em experimentos de campo, sob diferentes volumes de aplicação de água via irrigação. A produtividade de grãos foi inversa à média geral do Estado, nos dois anos analisados. Em 1998/1999, durante uma estiagem longa, 46,8 mm de chuva no período crítico garantiram rendimento próximo de $8.000 \mathrm{~kg} \mathrm{ha}^{-1}$ sem irrigação. Em 2002/2003 uma curta estiagem no período crítico reduziu a produtividade para menos de $2.000 \mathrm{~kg} \mathrm{ha}^{-1}$ no mesmo tratamento, afetando o número de espigas por planta e o número de grãos por espiga. Portanto, em anos de El Niño, mesmo que as previsões climáticas apontem para uma distribuição favorável de chuvas, há risco na produção esperada de milho, se o suprimento de água no período crítico da cultura não for adequado.

Termos para indexação: déficit hídrico, irrigação, componentes do rendimento, risco climático.

\section{Water supply in the critical period of maize and the grain production}

Abstract - Maize crops may experience reductions of grain yields when submitted to water deficit during the critical period of crop cycle, from tasseling stage to beginning of grain filling. The objective of this work was to demonstrate the importance of the water supply during the critical period on the grain production of maize. Experiments were conducted in Eldorado do Sul, Brazil ( $30^{\circ} 5^{\prime} \mathrm{S} ; 51^{\circ} 40^{\prime} \mathrm{W} ; 40 \mathrm{~m}$ altitude), during the crop seasons of 1998/1999 and 2002/2003, characterized by La Niña and El Niño phenomenon, respectively. Data of grain yield and its components were obtained in field experiments, using different volumes of water applied through irrigation. The grain yields showed an opposite tendency when compared to the regional estimated average. In 1998/1999, during a long drought period, $46.8 \mathrm{~mm}$ of rain on the critical period allowed a grain yield of about $8 \mathrm{tha}^{-1}$ without irrigation. In contrast, in 2002/2003 a short drought during the critical period reduced the grain yield to less than $2 \mathrm{tha}^{-1}$, affecting the number of ear per plant and the number of kernel per ear. Therefore, risks in the expected maize production are probable, although having climatic forecasting of favorable rain distribution in the region, such as by El Niño phenomenon.

Index terms: water deficit, irrigation, yield components, climatic risk.

\section{Introdução}

O milho pertence ao grupo de plantas com metabolismo fotossintético do tipo $\mathrm{C}_{4}$, que se caracteriza pelo elevado potencial produtivo. Entre as plantas $\mathrm{C}_{4}$, o milho está no grupo de espécies com maior eficiência de uso da radiação solar ou eficiência quântica, com valor médio entre 64,5 a $69 \mathrm{mmol} \mathrm{mol}^{-1}$, enquanto outras espécies $\mathrm{C}_{4}$ apresentam valores em torno de 52,6 a $60,4 \mathrm{mmol} \mathrm{mol}^{-1}$. Esta maior eficiência é atribuída à anatomia foliar, por apresentar menor área entre as nervuras e lamela suberizada, o que previne a perda de $\mathrm{CO}_{2}$ para o meio (Hattersley, 1984). Várias respostas do milho aos fatores do ambiente decorrem de seu mecanismo fotossintético $\mathrm{C}_{4}$, resultando em elevada produtividade de grãos, quando comparado a outras espécies cultivadas sem o mesmo mecanismo (Bergonci \& Bergamaschi, 2002).

O milho praticamente não apresenta saturação por radiação solar, pelo fato de ser uma planta $C_{4}$. O mecanismo de concentração deste composto provoca uma saturação deste composto no sítio da enzima 
rubisco, não permitindo a limitação da carboxilação (Taiz $\&$ Zeiger, 2004). No entanto, essa cultura apresenta um período crítico, que vai da pré-floração ao início do enchimento de grãos (Morizet \& Togola, 1984). Nessa etapa fenológica, o milho é sensível ao déficit hídrico, podendo-se observar esta sensibilidade nos processos fisiológicos ligados à formação do zigoto e início do enchimento de grãos, e na elevada transpiração que ocorre nesse período, em razão do maior índice de área foliar. Os eventos de formação do zigoto e início do crescimento dos grãos são muito suscetíveis a estresses, sobretudo ao déficit hídrico (Schussler \& Westgate, 1991a; Zinselmeier et al., 1995).

Por ser uma espécie de metabolismo $\mathrm{C}_{4}$, o milho tende a expressar sua elevada produtividade quando a máxima área foliar coincidir com a maior disponibilidade de radiação solar, desde que não haja déficit hídrico Essa condição permite a máxima fotossíntese possível, porém aumenta a necessidade hídrica da cultura, já que o elevado fluxo energético incidente também eleva evapotranspiração. No Estado do Rio Grande do Sul, Bergamaschi et al. (2001) observaram que a cultura do milho necessita em torno de $7 \mathrm{~mm}$ por dia de água durante o florescimento, quando este ocorre próximo ao solstício de verão, que é o período de máxima radiação solar. Com 67 mil plantas por hectare, um híbrido precoce de milho necessita de uma média de $650 \mathrm{~mm}$ de água em todo o ciclo (Bergamaschi et al., 2001). No entanto, numa população de 50 mil plantas por hectare, a necessidade média é de $577 \mathrm{~mm}$ para todo o ciclo do milho, na mesma região (Matzenauer et al., 1983). Isso demonstra a necessidade de um planejamento adequado de práticas de manejo para adequar as populações de plantas às reais condições pedoclimáticas, principalmente em lavouras que não dispõem de irrigação, a fim de reduzir os riscos causados por déficit hídrico.

Quando o déficit hídrico ocorre durante o período crítico da cultura, a produtividade de grãos é afetada, reduzindo, principalmente, o número de grãos por espiga (Matzenauer, 1994; Bergonci et al., 2001). Nessas condições, o uso da irrigação torna-se fundamental, pois é no período crítico que ocorrem os maiores efeitos do déficit hídrico e também a maior eficiência do uso da irrigação, tanto na produção de matéria seca quanto na produtividade de grãos. No Estado do Rio Grande do Sul, esta tendência foi verificada nos anos de 1993/1994 e 1996/1997, quando ocorreu déficit hídrico durante o período crítico da cultura do milho (Bergonci \& Bergamaschi, 2002).
A água é o principal fator condicionante das safras de milho de verão no Estado do Rio Grande do Sul, a exemplo do que ocorre nas regiões produtoras deste cereal do mundo. As estatísticas de produção revelam que, nos anos em que ocorrem períodos secos durante os meses de verão, a produtividade das culturas de verão é reduzida, causando prejuízos às cadeias produtivas (Matzenauer et al., 2002). Por este motivo, é importante compreender e quantificar os processos que envolvem relações clima-planta, em particular as relações hídricas, a fim de implementar medidas capazes de reduzir os impactos das estiagens sobre a produção dessas espécies.

Este trabalho teve por objetivo estabelecer relações entre o suprimento de água durante o período crítico do milho e a produção de grãos.

\section{Material e Métodos}

Foram utilizados dados de campo de experimentos conduzidos nas safras 1998/1999 e 2002/2003, na Estação Experimental Agronômica da UFRGS (EEA/ UFRGS), localizada no Município de Eldorado do Sul, na Depressão Central do Estado do Rio Grande do Sul (latitude $30^{\circ} 5^{\prime} \mathrm{S}$, longitude $51^{\circ} 40^{\prime} \mathrm{W}, 40 \mathrm{~m}$ de altitude). O clima da região é do tipo fundamental $\mathrm{Cfa}$, conforme a classificação climática de Köppen, ou seja, subtropical úmido com verão quente. A precipitação pluvial média anual é de $1.445 \mathrm{~mm}$ e a média anual de evapotranspiração de referência (Penman) é de $1.210 \mathrm{~mm}$. Segundo as normais climatológicas do local, os meses de novembro a fevereiro, que abrangem o período experimental, totalizam $442 \mathrm{~mm}$ de precipitação pluvial normal e $566 \mathrm{~mm}$ de evapotranspiração de referência normal (Bergamaschi et al., 2003). O solo da área experimental é classificado como Argissolo Vermelho distrófico típico (Embrapa, 1999).

Na safra 1998/1999, foi utilizado o híbrido precoce Pionner 3063 em 22/10/98, numa área de 0,54 ha. Em 2002/2003, em área de 0,50 ha, adjacente à primeira, utilizou-se o híbrido simples precoce Pionner 32R21, em 25/11/2002. Os dados de planta avaliados foram coletados na metade de cada área experimental.

A cultura foi implantada dentro de um sistema de sucessão de milho no verão, com preparo convencional, e consórcio de aveia/ervilhaca no inverno, em semeadura direta. Antes da semeadura do milho foi feita a incorporação da biomassa verde de aveia/ervilhaca, na base de 4 a 6 t ha $^{-1}$ de biomassa seca, com arado de disco e grade niveladora. 
A cultura foi semeada em fileiras, com espaços de 0,75 m, na direção leste-oeste, alcançando-se uma população aproximada de 67 e 65 mil plantas por hectare no primeiro e no segundo experimento, respectivamente. A adubação de base constou de 40, 160 e $160 \mathrm{~kg} \mathrm{ha}^{-1}$ de $\mathrm{N}, \mathrm{P}_{2} \mathrm{O}_{5}$ e $\mathrm{K}_{2} \mathrm{O}$, na forma de uréia, superfosfato triplo e cloreto de potássio, respectivamente. Em torno de 20 e 30 dias após a emergência, foram feitas duas aplicações, em cobertura, de $60 \mathrm{~kg} \mathrm{ha}^{-1}$ de nitrogênio na forma de uréia. Os demais tratos culturais, como controle de plantas daninhas e pragas foram feitos conforme a necessidade, utilizando-se defensivos recomendados.

No centro da área experimental, na direção das fileiras de plantas, foi instalada uma linha de aspersores distanciados $6 \mathrm{~m}$ entre si. Esta configuração permitiu a formação de um gradiente de irrigação em cada metade da área, promovendo diferentes condições de disponibilidade hídrica. Na faixa junto à linha de aspersores, que recebia a maior dose de rega, a umidade do solo foi mantida próximo à capacidade de campo. À medida que as demais faixas se distanciavam da linha de irrigação, havia redução no volume de água aplicada até o limite de alcance da aspersão, fora do qual a cultura não foi irrigada.

O monitoramento da umidade do solo foi feito com tensiômetros de coluna de mercúrio, cujas leituras foram utilizadas para definir o momento de irrigar As irrigações foram feitas sempre que o potencial da água no solo a $0,45 \mathrm{~m}$ de profundidade era inferior a $-0,06 \mathrm{MPa}$, nas parcelas próximas à linha de aspersores. O volume de água aplicada em cada irrigação foi determinado em um lisímetro de pesagem cultivado com milho e instalado no centro da área experimental.

Em função da configuração experimental, foi adotado um delineamento em faixas, com quatro repetições, conforme Hanks et al. (1976, 1980). As faixas iniciavam-se rente à linha dos aspersores e tinham largura de $3,00 \mathrm{~m}$, com quatro fileiras de plantas, que formavam a unidade experimental. No ano de 1998/1999, foram aplicados cinco tratamentos de irrigação, correspondentes a 100,93,60, 54, 7,5 e 0\% do volume máximo necessário para elevar a umidade do solo até a capacidade de campo. Em 2002/2003, o sistema permitiu quatro diferentes tratamentos de irrigação, correspondentes a 100, 41,20 e $0 \%$ do volume máximo aplicado, já que as duas primeiras faixas não apresentaram diferença no volume de irrigação.

Para as determinações da produtividade de grãos e seus componentes, foi colhida uma área de $15 \mathrm{~m}^{2}$, a qual correspondia às duas linhas centrais de cada unidade experimental. Foram colhidas todas as espigas existentes com, pelo menos, um grão formado. No momento da colheita, foram contados o número de espigas e o número de plantas em cada parcela colhida. Do total de espigas colhidas em cada unidade experimental foram selecionadas, ao acaso, dez espigas para a determinação dos demais componentes da produção.

Foi determinado o número de grãos por espiga, a partir do número médio de grãos de quatro fileiras multiplicado pelo número de fileiras da respectiva espiga. Na determinação do peso médio de 100 grãos, foram separadas quatro amostras aleatórias de cada unidade experimental para compor um valor médio da parcela. Tanto o peso de 100 grãos quanto a produtividade de grãos foram calculados em base de $13 \%$ de umidade.

Numa estação meteorológica automática modelo Campbell, localizada junto à área experimental, foram coletados dados diários de precipitação pluvial e outras variáveis necessárias à estimativa da evapotranspiração de referência pelo método de Penman, as quais foram utilizadas na caracterização das condições meteorológicas durante o ciclo da cultura.

Com o uso de análise de regressão, pelo método dos mínimos quadrados, foram analisadas as respostas da cultura ao fator água, para cada ano e para cada atributo avaliado. Modelos quadráticos foram ajustados de modo a verificar as respostas da cultura aos níveis de água aplicada. Nas figuras são apresentadas as curvas de tendência e os pontos correspondentes às médias por tratamento. Os coeficientes de determinação $\left(R^{2}\right)$ e os respectivos graus de significância foram obtidos a partir das repetições.

\section{Resultados e Discussão}

Os anos agrícolas de 1998/1999 e 2002/2003 estiveram sob a influência de condições distintas quanto ao fenômeno de grande escala El Niño e La Niña - Oscilação Sul (ENOS). No primeiro ano, prevaleceu a condição La Niña, que está associada a precipitações abaixo da média histórica do Estado, enquanto no segundo ano a condição estabelecida foi de El Niño, que está associada a chuvas acima da média histórica (Berlato \& Fontana, 2003). As duas fases do fenômeno apresentam as maiores anomalias pluviométricas no período de primavera-verão, especialmente nos meses de outubro e novembro, que também é o período de crescimento e desenvolvimento das culturas de verão. Entre es- 
sas culturas encontra-se o milho que, por ter um período crítico bem definido, torna-se sensível aos efeitos dessas condições e, por isso, sujeito a grandes impactos de produtividade.

As estatísticas de produção de milho no Rio Grande do Sul, nos dois anos analisados (Tabela 1), são coerentes com a condição climática prevista para cada safra. A condição de La Niña, na safra 1998/1999, causou redução na produção de milho no Estado, com sérios prejuízos aos produtores e à cadeia produtiva ligada ao cereal. A redução na safra foi conseqüência da estiagem prolongada que ocorreu nos meses de dezembro e janeiro, quando a grande maioria das lavouras de milho do Estado encontrava-se no período crítico, ou seja do pendoamento ao início de enchimento de grãos. Na safra 2002/2003 foram verificadas precipitações acima das médias climáticas, associadas à condição de El Niño. Nesse ano, a produção de milho foi elevada no Estado do Rio Grande do Sul, atendendo à demanda de consumo interno, e a produtividade de grãos superou a média histórica de $2.200 \mathrm{~kg} \mathrm{ha}^{-1}$ (Matzenauer et al., 2002).

A situação apresentada pode ser considerada como representativa da condição média de produção de milho no Estado do Rio Grande do Sul em anos de La Niña El Niño, respectivamente. Por sua vez, os resultados dos experimentos conduzidos na Estação Experimental Agronômica da UFRGS, nas mesmas safras (Figura 1), demonstraram que a cultura do milho apresentou tendência oposta às médias estaduais. Na ausência de irrigação, a produtividade de grãos foi superior a $8.000 \mathrm{~kg} \mathrm{ha}^{-1}$ na safra 1998/1999, na condição de La Niña, e inferior a $2.000 \mathrm{~kg} \mathrm{ha}^{-1}$ na safra de 2002/2003, na qual prevaleceu a condição de El Niño. Considerando como produtividade potencial aquela alcançada no maior nível de irrigação, verifica-se que a queda na produção de grãos foi maior no ano em que o Estado do Rio Grande do Sul produziu sua maior safra de milho dos últimos tempos (2002/2003).

Tabela 1. Estatísticas de produção de milho no Estado do Rio Grande do Sul, em anos com diferentes condições pluviométricas, associadas ao fenômeno El Niño/La Niña.

\begin{tabular}{lcccc}
\hline Safra & $\begin{array}{c}\text { Área } \\
\text { colhida (ha) }\end{array}$ & $\begin{array}{c}\text { Produção } \\
\text { total (t) }\end{array}$ & $\begin{array}{c}\text { Grãos } \\
\text { (kg/ha) }\end{array}$ & $\begin{array}{c}\text { Condição } \\
\text { climática }\end{array}$ \\
\hline $1998 / 1999$ & 1.326 .085 & 3.211 .333 & 2.422 & La Niña \\
$2002 / 2003$ & 1.408 .900 & 5.283 .400 & 3.750 & El Niño \\
\hline
\end{tabular}

\begin{tabular}{lll}
$2002 / 2003$ & 1.408 .900 & 5.283 .400 \\
\hline
\end{tabular}

Fonte: Conab (2004) e Fecoagro (2004)
O contraste de variação entre as médias de produtividade do Estado e dos experimentos avaliados, nas épocas de cultivo analisadas, demonstram a importância da variabilidade na distribuição das precipitações de verão no Rio Grande do Sul. Nas culturas de primavera-verão, a variabilidade pluviométrica pode ser responsável tanto por elevada produtividade, quando o balanço hídrico no solo no período crítico é positivo em anos adversos, quanto por reduções de safras em anos com potencial para alta produção, se o balanço hídrico for negativo no mesmo período. Quanto ao milho, associada à variabilidade climática, há grande sensibilidade da cultura, em razão de seu período crítico curto e bem definido, desde a emissão da inflorescência masculina (pendoamento) até o início do enchimento de grãos. Por este motivo, os resultados dos dois anos agrícolas analisados apresentaram padrão inverso, na comparação das médias observadas em todo o Estado e nos experimentos avaliados.

No ano agrícola de 1998/99, em decorrência do fenômeno La Niña, houve uma longa estiagem na maior parte do Rio Grande do Sul, que explica a redução da produtividade média do Estado. Nos experimentos avaliados e áreas próximas, houve duas precipitações aos 73 e 78 dias após emergência (Figura 2), entre o pendoamento e o espigamento, que totalizaram $46,8 \mathrm{~mm}$. Essas precipitações umedeceram o solo até a profundidade de $60 \mathrm{~cm}$, conforme dados de tensiometria apresentados por Müller (2001). A produtividade das parcelas não irrigadas, em torno de $8.000 \mathrm{~kg} \mathrm{ha}^{-1}$ de grãos (Figura 3), pode ser atribuída a esta precipitação localizada, típica

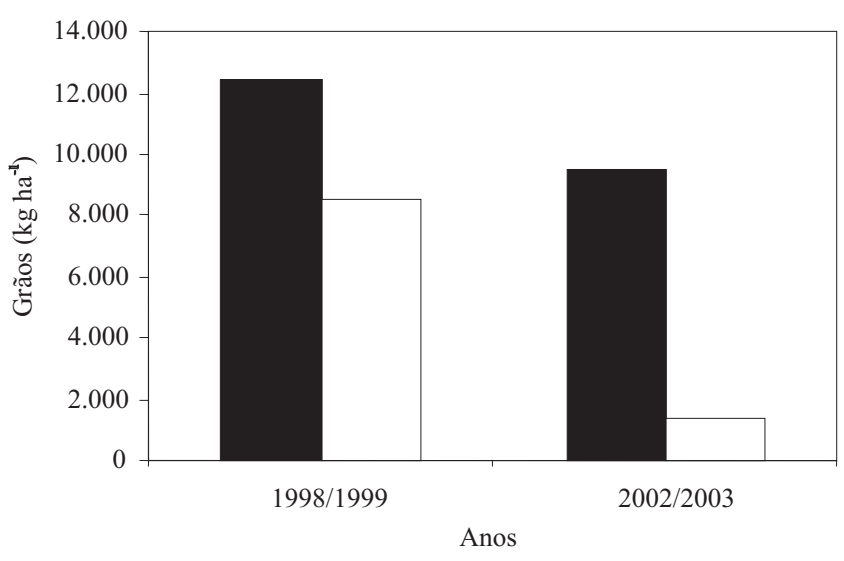

Figura 1. Produtividade de grãos de milho, híbridos Pioneer 3063 (1998/1999) e Pioneer 33R21 (2002/2003), irrigado (ロ) e não irrigado $(\square)$. 
de formação convectiva de final de tarde no verão, a qual teve o efeito que uma única irrigação teria, se fosse feita durante o florescimento da cultura.

Condição contrária foi verificada na safra de 2002/ 2003, quando o Estado registrou precipitações acima da média e relativamente bem distribuídas nas principais regiões produtores de milho. Nos experimentos avalia- dos e em áreas próximas, houve uma curta estiagem, com elevada demanda evaporativa atmosférica num intervalo contínuo de aproximadamente oito dias, ao redor dos 60 dias após a emergência (Figura 2). Esta condição provocou intenso déficit hídrico às plantas no início do pendoamento, quando o milho mais necessitava de água. Cerca de três a quatro dias após o início do
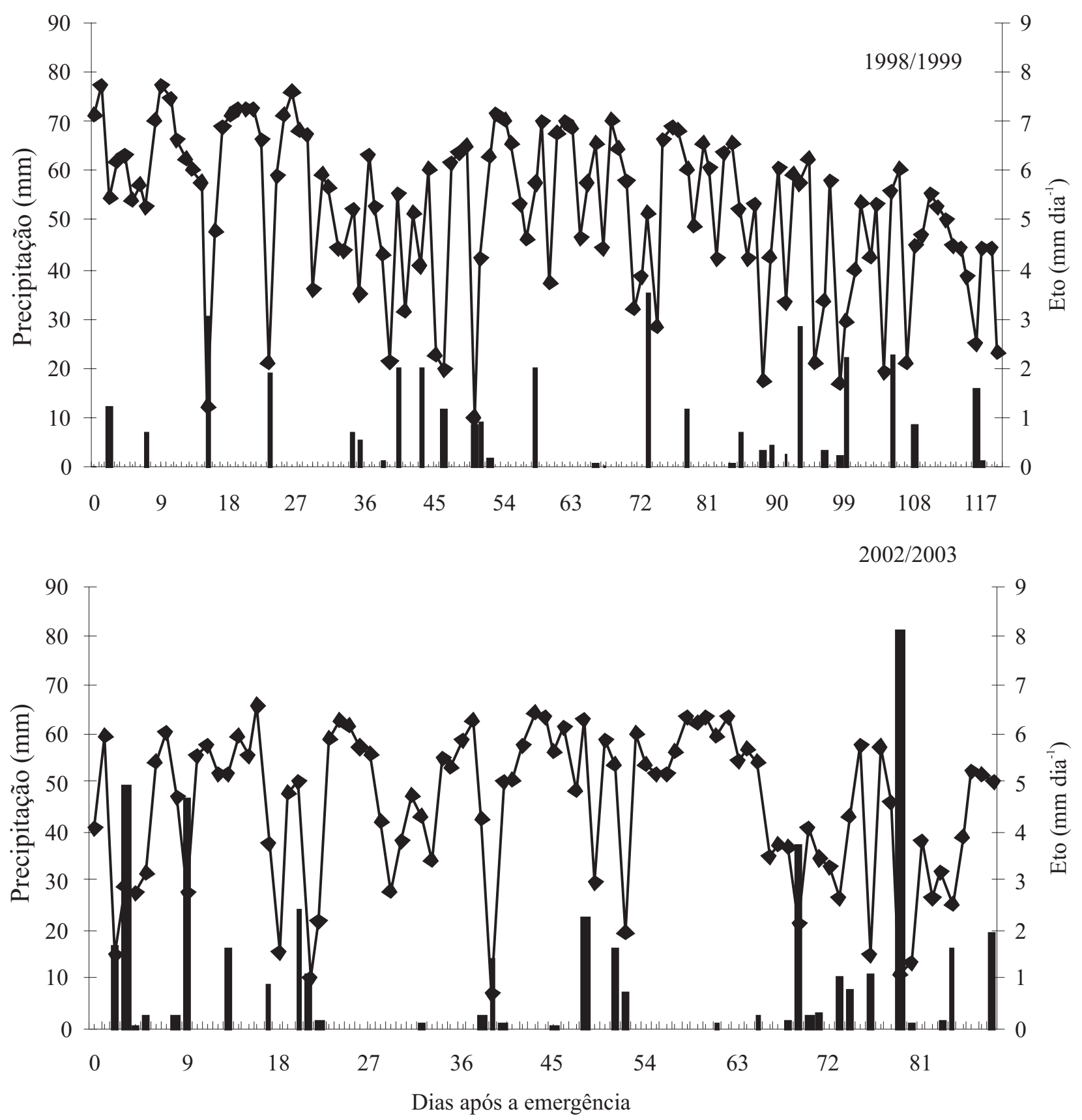

Figura 2. Precipitação pluvial (ロ) e evapotranspiração de referência (Eto) $(\bullet)$, totais diários, ocorridos nos anos agrícolas de 1998/1999 e 2002/2003 em razão de dias após a emergência do milho. 
déficit hídrico, muitas plantas não mais conseguiram atingir a recuperação hídrica noturna (Dalmago et al., 2003), apresentando-se murchas no início da manhã. O déficit hídrico causou um forte impacto na produtividade de grãos não irrigada, que se manteve abaixo de $2.000 \mathrm{~kg} \mathrm{ha}^{-1}$ enquanto a área irrigada produziu cerca de $10.000 \mathrm{~kg} \mathrm{ha}^{-1}$

O potencial de produção mais elevado observado em parcelas irrigadas no ano agrícola 1998/1999 pode ser atribuído ao efeito de época de semeadura de final de outubro, comparado ao ano agrícola de 2002/2003, em que a cultura foi semeada no final de novembro. As semeaduras em final de outubro propiciam máxima área foliar em final de dezembro e início de janeiro, quando há maior incidência de radiação solar na região. Por sua vez, em semeaduras de final de novembro, a área foliar máxima ocorre em fins de janeiro, período em que a radiação solar é menor em relação ao final de dezembro. Didonet et al. (2002) também atribuem as maiores produtividades de milho em semeaduras feitas em outubro, em relação àquelas feitas em final de novembro, à maior relação possível entre a radiação solar e a temperatura do ar até o espigamento (coeficiente fototérmico).

A resposta da produção de grãos à irrigação, no ano 2002/2003, evidencia a elevada necessidade de água pelo milho no período crítico (Figura 3). Porém, a cultura também apresentou alta produção de grãos com irrigações entre 60 e $80 \%$ da necessária para elevar a umidade do solo à capacidade de campo, confirmando resultados anteriores de Bergonci et al. (2001). Isso reafirma a idéia

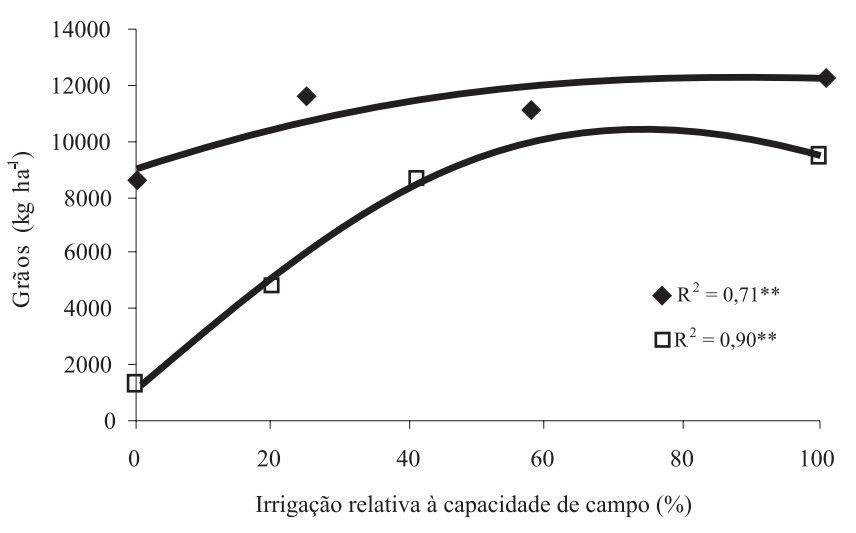

Figura 3. Produtividades de grãos de milho híbrido Pioneer 3063 na safra 1998/1999 ( ) e Pioneer 33R21 na safra 2002/ 2003 (ㅁ) em razão de níveis de irrigação relativos à capacidade de campo.

Pesq. agropec. bras., Brasília, v.39, n.9, p.831-839, set. 2004 de que a quantidade de água a ser aplicada não é o principal fator a ser observado no manejo da irrigação. O uso adequado da irrigação deve considerar, sobretudo, o momento em que a planta mais necessita de água, a fim de se obter maior eficiência. É indispensável considerar esses aspectos na implementação de sistemas de monitoramento agrometeorológico eficientes, a fim de manejar a cultura dentro do conceito de precisão na agricultura, alocando recursos de produção, como a água, no momento em que as plantas mais necessitam.

Na safra 2002/2003 foram afetados, principalmente, o número de espigas por planta e o número de grãos por espiga (Figura 4). Estes componentes são definidos no período crítico da cultura e, portanto, sofreram efeitos mais intensos do déficit hídrico daquele momento. De acordo com Herrero \& Johnson (1981), o déficit hídrico parece afetar, principalmente, o desenvolvimento dos órgãos florais masculinos, bem como a germinação do pólen. Schussler \& Westgate (1991b) sugerem que a redução do número de grãos por espiga, em plantas submetidas a déficit hídrico, se deve à baixa taxa de suprimento de assimilados aos ovários, provocando abortamento.

O tamanho dos grãos foi menos afetado, por depender da condição hídrica posterior, durante o enchimento de grãos, a qual foi satisfatoriamente atendida (Figura 2). No caso da safra 1998/1999, a redução na produção de grãos da área não irrigada pode ser atribuída, exclusivamente, à redução do peso de 100 grãos (Figura 4). Este componente foi afetado pela manutenção da condição restritiva de água às plantas depois da chuva ocorrida cerca de 60 dias após a emergência (Figura 2).

Plantas submetidas ao déficit hídrico do pendoamento ao início de enchimento de grãos (safra 2002/2003) apresentaram grande número de espigas sem grãos ou espigas com poucos grãos. Isso se deve ao fato de que as plantas emitiram a inflorescência masculina no momento em que se iniciou o déficit hídrico, 55 dias após semeadura. Nessa condição, muitas atrasaram a emissão das espigas, 63 dias após semeadura, quebrando o sincronismo entre emissão dos estigmas e liberação do pólen, justificando a ocorrência de espigas com poucos grãos ou sem grãos. A redução do número de espigas também pode ser atribuída ao atraso provocado pelo déficit hídrico na emissão da mesma, o que levou muitas plantas a perderem sua capacidade de emissão de espigas por causa do estado debilitado em que se encontra- 
vam ao final da restrição hídrica. Tal evidência está de acordo com Guei \& Wasson (1992), que constataram influência do estresse por água e temperatura nas datas de florescimento masculino e feminino e na duração do intervalo entre antese e emissão de estigmas em milho.

A queda na produção de grãos na área não irrigada na safra 1998/1999, em relação às parcelas potenciais, pode ser atribuída ao efeito do déficit hídrico na redução do peso de 100 grãos. Depois da chuva ocorrida aos 60 dias após a emergência, houve um período de restrição hídrica à cultura na área não irrigada (Figura 2). Isso pode ter afetado a primeira etapa da fertilização (etapa de retardamento), que é a divisão celular (Johnson \& Tanner, 1972), mais sensível ao déficit hídrico em relação às demais etapas (Quattar et al., 1987).

Este conjunto de resultados ressalta a elevada sensibilidade do milho ao déficit hídrico do florescimento ao início de formação de grãos. Neste período, somente a chuva e a irrigação podem manter a produtividade de grãos em níveis elevados, da ordem de $8.000 \mathrm{~kg} \mathrm{ha}^{-1}$, se não houver limitações por outros fatores. Esta alta
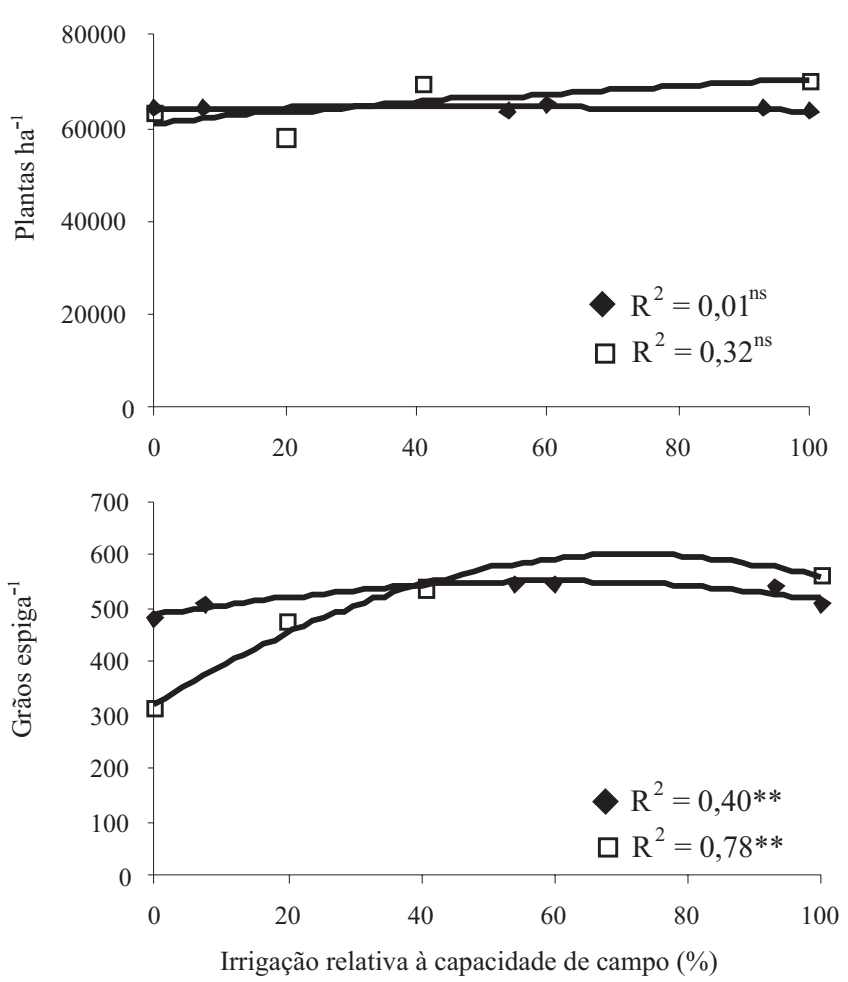

sensibilidade da cultura, em um período relativamente curto, associada à grande variabilidade na distribuição de chuvas durante a estação quente, faz do milho uma cultura altamente suscetível ao fator água. Isso se traduz em alto risco ao produtor, mesmo que a tendência da safra seja de chuvas acima da condição climática média, como em anos de El Niño.

Em anos de estiagem, a cultura poderá ter desempenho adequado, em algumas épocas, contando que haja suprimento hídrico no período crítico. Desta forma, a irrigação apenas neste período poderá garantir produtividade satisfatória, mesmo que a cultura sofra restrições no restante do ciclo (Matzenauer, 1994; Bergonci et al., 2001). Portanto, a irrigação na cultura do milho, antes de representar a aplicação de grande quantidade de água, significa atender à necessidade hídrica no período crítico. A quantidade de água necessária para obter adequada produtividade não é elevada, o que pode ser relevante em pequenas propriedades, principalmente naquelas com restrições quanto a mananciais ou equipamento disponível.
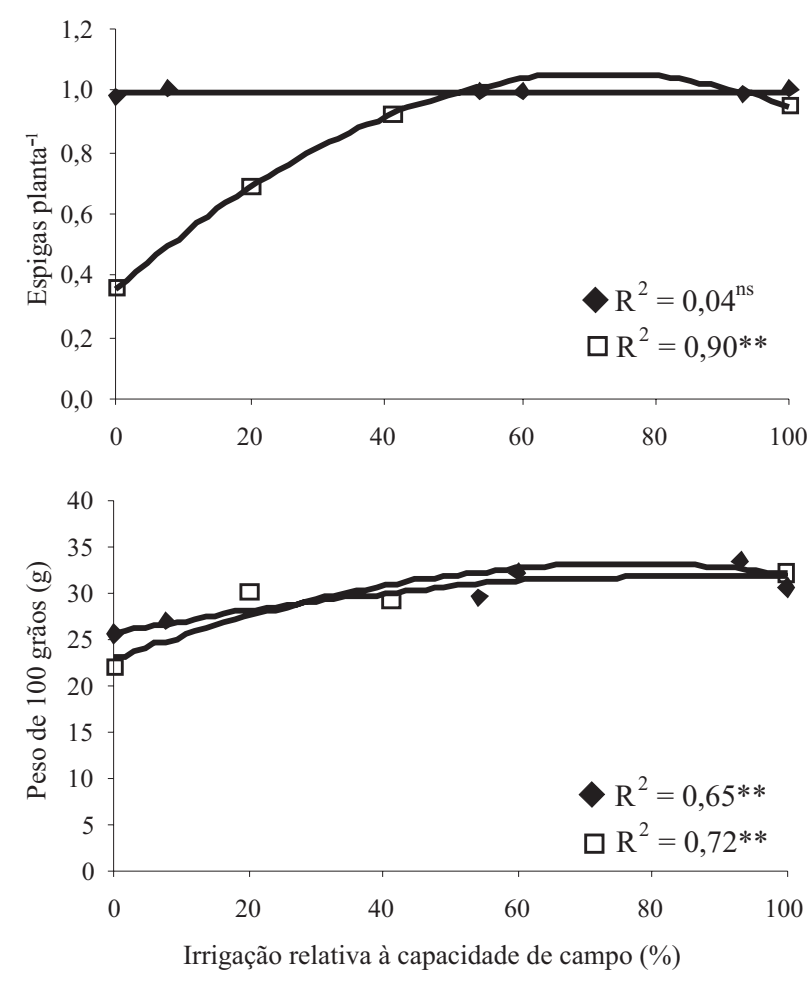

Figura 4. Componentes da produção de grãos do milho híbrido Pioneer 32R21 na safra 2002/2003 (ㅁ) e do híbrido Pioneer 3063 na safra 1998/1999 ( ) em razão de lâminas de irrigação relativas à capacidade de campo. 


\section{Conclusões}

1. Independentemente da condição climática regional, a produtividade de grãos de milho é decorrente das condições hídricas durante o período crítico, que vai do pendoamento ao início do enchimento de grãos.

2. Irrigações durante o período que vai do pendoamento ao início de enchimento de grãos permitem elevada produtividade de grãos de milho, mesmo que a umidade do solo seja mantida abaixo da capacidade de campo.

3. O número de grãos por espiga e o número de espigas por planta são os componentes da produção de grãos mais afetados pelo déficit hídrico, quando este ocorre durante o período crítico do milho.

\section{Agradecimentos}

Ao $\mathrm{CNPq}$ pela concessão de bolsa aos autore Homero Bergamaschi, Genei Antonio Dalmago, Flávia Comiram e Bruna Maria Machado Heckler; à Capes pela concessão de bolsa à autora Cleusa Adriane Menegassi Bianchi.

\section{Referências}

BERGAMASCHI, H.; GUADAGNIN, M.R.; CARDOSO, L.S SILVA, M.I.G da. Clima da Estação Experimental da UFRGS (e região de abrangência). Porto Alegre: UFRGS, 2003. 77p. BERGAMASCHI, H.; RADIN, B.; ROSA, L.M.G.; BERGONCI, J.I.; ARAGONÉS, R.; SANTOS, A.O.; FRANÇA, S. LANGENSIEPEN, M. Estimating maize water requirements using agrometeorological data. Revista Argentina de Agrometeorologia v.1, p.23-27, 2001

BERGONCI, J.I.; BERGAMASCHI, H. Ecofisiologia do milho. In CONGRESSO NACIONAL DE MILHO E SORGO, 24., 2002, Florianópolis. Anais. Florianópolis: Embrapa Milho e Sorgo; Epagri, 2002. CD-ROM.

BERGONCI, J.I.; BERGAMASCHI, H.; SANTOS, A.O FRANÇA, S.; RADIN, B. Eficiência da irrigação em rendimento de grãos e matéria seca de milho. Pesquisa Agropecuária Brasileira v.36, p.949-956, 2001.

BERLATO, M.A.; FONTANA, D.C. El Niño e La Niña: impactos no clima, na vegetação e na agricultura do Rio Grande do Sul; aplicaçõe de previsões climáticas na agricultura. Porto Alegre: Editora da UFRGS, 2003. 110p.

CONAB. Quinto levantamento safra 2003/2004, junho 2004 Brasília. Disponível em: <http://www.conab.gov.br> Acesso em: 3 ago. 2004.

DALMAGO, G.A.; BERGAMASCHI, H.; BERGONCI, J.I.; BIANCHI, C.A.M.; HECKLER, B.M.M. Transpiração do milho cultivado em sistemas de semeadura direta e convencional. In: CONGRESSO BRASILEIRO DE AGROMETEOROLOGIA, 13. 2003, Santa Maria, RS. Anais. Santa Maria: SBA; UFSM; UNIFRA, 2003. v.1, p.297-298.

DIDONET, A.D.; RODRIGUES, O.; MARIO, J.L.; IDE, F. Efeito da radiação solar e temperatura na definição do número de grãos em milho. Pesquisa Agropecuária Brasileira, v.37, p.933-938, 2002.

EMBRAPA. Centro Nacional de Pesquisa de Solos (Rio de Janeiro, RJ). Sistema brasileiro de classificação de solos. Brasília: Embrapa-SPI; Embrapa-CNPS, 1999. 412p.

FECOAGRO/RS. Milho, Rio Grande do Sul. Porto Alegre. Disponível em: 〈http://www.redeagro.com.br/indica/milho.htm> Acesso em: 3 ago. 2004

GUEI, R.G.; WASSON, C.E. Inheritance of some drought adaptative traits in maize: I. Interrelationships between yield, flowering, and ears per plant. Maydica, v.37, p.157-164, 1992.

HANKS, R.J.; KELLER, J.; RASMUSSEN, V.P.; WILSON, G.D. Line source sprinkler for continuous variable irrigation crop production studies. Soil Science Society American Journal, v.40, p.426429, 1976.

HANKS, R.J.; SISSON, D.V.; HURST, R.L.; HUBBARD, K.G. Statistical analyss of results from irrigation: experiments using the line-source sprinkler system. Soil Science Society of American Journal, v.44, p.886-888, 1980.

HATTERSLEY, P.W. Characterization of $\mathrm{C}_{4}$ type leaf anatomy in grasses (Poaceae). Mesophyll:bundles sheath area ratios. Annual of Botany, v.53, p.163-179, 1984

HERRERO, M.P.; JOHNSON, R.R. Drought Stress and its effects on maize reproductive systems. Crop Science, v.21, p.105-110, 1981

JOHNSON, D.R.; TANNER, J.W. Calculation of the rate and duration of grain filling in corn (Zea mays L.). Crop Science, v.12, p.485-486, 1972.

MATZENAUER, R. Modelos agrometeorológicos para estimativa do rendimento de milho, em função da disponibilidade hídrica no Estado do Rio Grande do Sul. 1994. 172p. Tese (Doutorado) - Universidade Federal do Rio Grande do Sul, Porto Alegre.

MATZENAUER, R.; BERGAMASCHI, H.; BERLATO, M.A.; MALUF, J.R.T.; BARNI, N.A.; BUENO, A.C.; DIDONE, I.A.; ANJOS, C.S.; MACHADO, F.A.; SAMPAIO, M.R. Consumo de água e disponibilidade hídrica para milho e soja, no Rio Grande do Sul. Porto Alegre: Fepagro, 2002. 105p. (BOLETIM Fepagro, 10).

MATZENAUER, R.; WESTPHALEN, S.L.; BERGAMASCHI, H. Relações entre a evapotranspiração do milho e as fórmulas de Penman e Thornthwaite. Pesquisa Agropecuária Brasileira, v.18, p.1207-1214, 1983.

MORIZET, J.; TOGOLA, D. Effect et arrière-effect de la sécheresse sur la croissance de plusieurs génotipes de maïs. In: CONFÉRENCE INTERNATIONALE DES IRRIGATIONS ET DU DRAINAGE, 1984, Versailles. Les bésoins en eau des cultures. Paris: INRA 1984. p.351-360. 
MÜLLER, A.G. Modelagem da matéria seca e do rendiment de grãos de milho em relação à disponibilidade hídrica. 2001 120p. Tese (Doutorado) - Universidade Federal do Rio Grande do Sul, Porto Alegre.

QUATTAR, S.; JONES, R.J.; CROOKSTON, R.K. Effect of wate deficit during grain filling on the pattern of maize kernel growth an development. Crop Science, v.27, p.726-730, 1987.

SCHUSSLER, R.J.; WESTGATE, M.E. Maize kernel set at low potential: I. Sensivity to reduced assimilates during early kerne growth. Crop Science, v.31, p.1189-1195, 1991a.
SCHUSSLER, R.J.; WESTGATE, M.E. Maize kernel set at low potential: II. Sensivity to reduced assimilates at pollination. Crop Science, v.31, p.1196-1203, 1991b.

TAIZ, L.; ZEIGER, E. Fisiologia vegetal. Tradução Eliane Romanato Santarém et al. 3.ed. Porto Alegre: Artmed, 2004. 719p.

ZINSELMEIER, C.; WESTGATE, M.E.; JONES, R.J. Kernel set at low water potential does not vary with source/sink ratio in maize. Crop Science, v.35, p.158-163, 1995

$\overline{\text { Recebido em } 11 \text { de fevereiro de } 2004 \text { e aprovado em } 9 \text { de junho de } 2004}$ 